\title{
Expansion of student activities in Africa: from south to north
}

Rim Cherif, Amine Ben Salem, Amor Gueddana, Mourad Zghal, Darryl Naidoo, et al.

Rim Cherif, Amine Ben Salem, Amor Gueddana, Mourad Zghal, Darryl Naidoo, Andrew Forbes, Alexander M. Heidt, Erich G. Rohwer, "Expansion of student activities in Africa: from south to north," Proc. SPIE 9289, 12th Education and Training in Optics and Photonics Conference, 928914 (17 July 2014); doi: 10.1117/12.2070775

Event: 12th Education and Training in Optics and Photonics Conference, 2013, Porto, Portugal 


\title{
Expansion of student activities in Africa: from south to north
}

\author{
Rim Cherif ${ }^{1 *}$, Amine Ben Salem ${ }^{1}$, Amor Gueddana ${ }^{1}$, Mourad Zghal ${ }^{1}$, Darryl Naidoo ${ }^{2}$, Andrew \\ Forbes $^{2}$, Alexander M. Heidt ${ }^{3}$, and Erich G. Rohwer ${ }^{3}$ \\ ${ }^{1}$ Engineering school of communications of Tunis (Sup'Com), University of Carthage, Route de \\ Raoued, 2083 El Ghazala, Tunis, Tunisia. \\ ${ }^{2}$ CSIR National Laser Centre, PO Box 395, Pretoria 0001, South Africa. \\ ${ }^{3}$ Laser Research Institute, University of Stellenbosch, PO Box 3300, Matieland 7602, South Africa.
}

\begin{abstract}
Optics and photonics research in Africa has gradually grown in the past ten years with a very active optical community involved in state-of-the-art research. Despite relatively low resources, optics research in the continent is competitive with many international benchmarks and has had a significant impact within the African continent. In the past five years, a group of dynamic students have developed the student chapter network from Tunisia to South Africa. The first student chapters of the optical society of America (OSA) and the international society for optics and photonics (SPIE) were established in South Africa (in the Council for Scientific and Industrial Research (CSIR) and in the University of Stellenbosch), followed by a chapter in Tunisia (Engineering school of communications of Tunis, Sup'Com). In this paper, we will present the major activities of the student chapters of Tunisia and South Africa, and how they are promoting optics and photonics in Africa.
\end{abstract}

Keywords: promoting optics and photonics, African student chapters, outreach, education, technical skills.

\section{INTRODUCTION}

The idea behind creating student chapters is to promote the optical knowledge into the community and create real technical and leadership skills. This objective has been launched by professional societies namely OSA and SPIE which create the concept of student chapter and allow them to exist in different continents. The student chapters receive funding and networking from these international organizations aiming to increase the interest in optics for different students (graduate and undergraduate) and provide the professional development of all the members.

In our case, from the south to the north of Africa, three student chapters with both OSA and SPIE endorsement have been founded. These chapters consist of two South African founded in 2008, one in the CSIR and the other in the University of Stellenbosch. The third one is the optics and photonics Tunisia student chapter (OPTSC) founded in 2009.

The activities of the chapters, driven by both graduate ( $\mathrm{PhD}$ and $\mathrm{MSc}$ ) and undergraduate students, include the promotion of science in general and optics in particular, with the aim of attracting more and more students into the field, thus enlarging the optics community in Africa. The activities are divided into three categories: education, seminars, and outreach. The chapters work on maintaining a strong leadership, motivation, and access to resources, so that they can reach large numbers of pre-college students through educational activities. Organizing regular seminars with pioneers in the field of optics and photonics gives the $\mathrm{PhD}$ and MSc students the opportunity to share their results and discuss them. Local and international outreach activities of the chapters have brought hands-on demonstration materials involving optics and photonics to thousands of students in secondary schools, including rural and underprivileged schools and communities, conveying the impact and fascination of modern optical technology. Visits of active researchers to school classes greatly improve the interest of the students in their science lessons by putting their knowledge into perspective with current research objectives and visions of the future. The visits can also trigger an early motivation in the students to consider a career in science and improve the acceptance of science and technology as a major factor in the growth and development of the continent.

*rim.cherif@supcom.rnu.tn, phone+216 71857 000; fax +216 71856 829; www.supcom.mincom.tn.

12th Education and Training in Optics and Photonics Conference, edited by

Manuel F. P. C. Martins Costa, Mourad Zghal, Proc. of SPIE Vol. 9289, 928914

(C) 2014 SPIE, OSA, IEEE, ICO · doi: 10.1117/12.2070775 


\section{STUDENT CHAPTER BENEFITS AND OBJECTIVES}

By the creation of an optical student chapter supported by rather OSA or SPIE, the chapter members find a great way to build technical and leadership skills while networking with peers and the greater OSA and SPIE community.

The structure of a student chapter is usually as follows: different members composed of graduate and undergraduate students and a professor of the same university who is involved as faculty advisor. Four student members take specific tasks in the chapter and ruled as officers: president, vice-president, treasurer and secretary. With such structure, the organization of educational and social activities will be defined. OSA and SPIE provide each chapter with a wide range of benefits and opportunities for professional development. In fact, activity grants to organize conferences or seminars are offered to encourage the members and endorse them. In addition, free outreach materials are eligible and could be used to facilitate and make demonstrations. The student chapter has the opportunity to invite a visiting lecturer through the traveling lecturer program in order to make the event more interesting and encourage people to attend and learn especially from well known scientific lecturers. A leadership conference attendance per year is possible through the student chapter by sending one delegate to learn more about other student chapter activities and establish social networking. Moreover, the OSA and SPIE provide free access of scientific articles, conference papers to their student members which encourage students to improve their optics career and build efficient technical skills.

By taking advantages of all these benefits, many activities could take place and be performed so that the knowledge of optics, pure and applied could be worldwide diffused. In addition, by organizing educational and outreach activities especially in the African countries which are still less developed compared to other continents, the research field of optics and photonics would be so promoting and advancing. Therefore, connecting the members with leaders from scientific institutions and companies employing physicists and engineers will establish real opportunities for scientific collaboration and potential employment after graduation. Thus, potential social and scientific networking with other OSA and SPIE Student chapters in Africa and all over the world will be achieved.

\section{AFRICAN STUDENT CHAPTER ACTIVITIES}

Several activities have been carried out by the different African student chapter. The first of these activities was through professional development activities. In fact, by receiving funding and support from OSA and SPIE, a guest speaker has been invited to give a plenary lecture to young students and get their interest to the field of optics and photonics. Therefore, students attending the event show their attention to join the student chapter and be active and looking for organizing other social and technical activities.

The Tunisian OPTSC, in April 2010, had the opportunity to invite many lecturers like Prof. John Dudley from the University of Franche-Comté, fellow of OSA through the travelling lecturer program to give talk on applications of nonlinear fiber optics, as seen from Fig. 1. The Tunisian student chapter set also a booth on the entrance of the engineering school of communication of Tunis (Sup'Com) in order to explain the mission of the student chapter and recruit new members, as seen from Fig. 1.

In December 2010, another workshop activity had been performed by the OPTSC at Sup'Com through the invitation of international lecturers. In fact, Prof. Maria Yzuel from the Universidad Autónoma de Barcelona, Spain, Immediate Past President of SPIE gave a seminar on "Liquid crystal panels in diffractive optics". Prof. Philippe Gallion from l'Ecole Nationale Supérieure des Télécommunications TELECOM ParisTech gave also a talk dealing with "Cryptographie quantique". The OPTSC was honored by the presence of Prof. Zohra Ben Lakhdar (Tunis El Manar University), Vice President of the International Commission of Optics (ICO), as seen from Fig. 1.

In December 2011, Prof. Maria L. Calvo from Universidad Complutense de Madrid, Immediate Past President of the ICO visited the OPTSC labs where they introduced for her the student chapter and presented their past activities. 


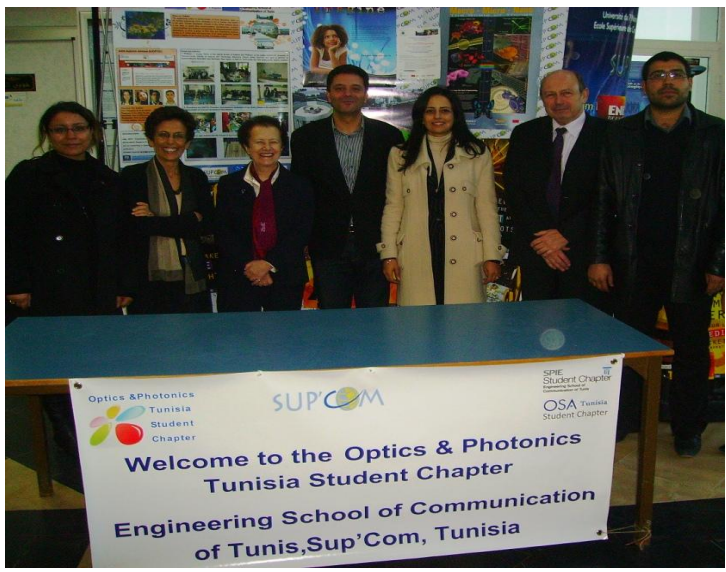

The OPTSC honored by the presence of Prof. Z. Ben Lakdhar and the invited lecturers (Prof. Yzuel and Prof. Gallion).

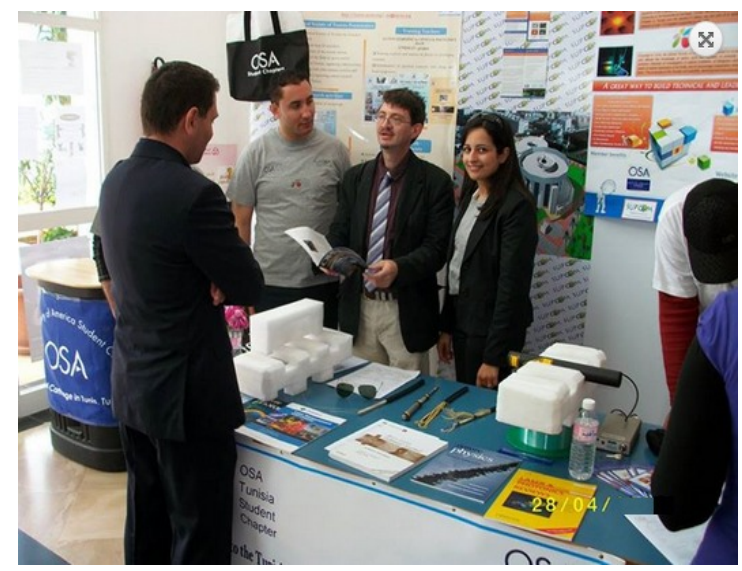

Booth set at the entrance of Sup'Com with Prof. John Dudley.

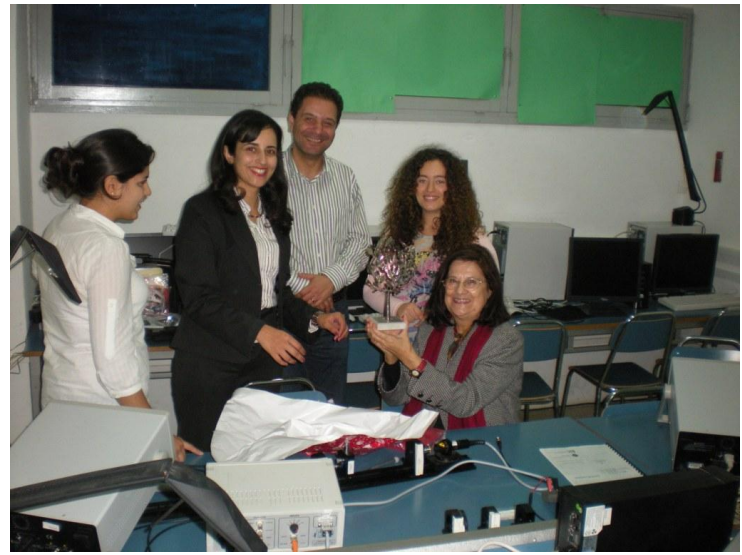

Prof. Maria Calvo visiting the OPTSC labs.

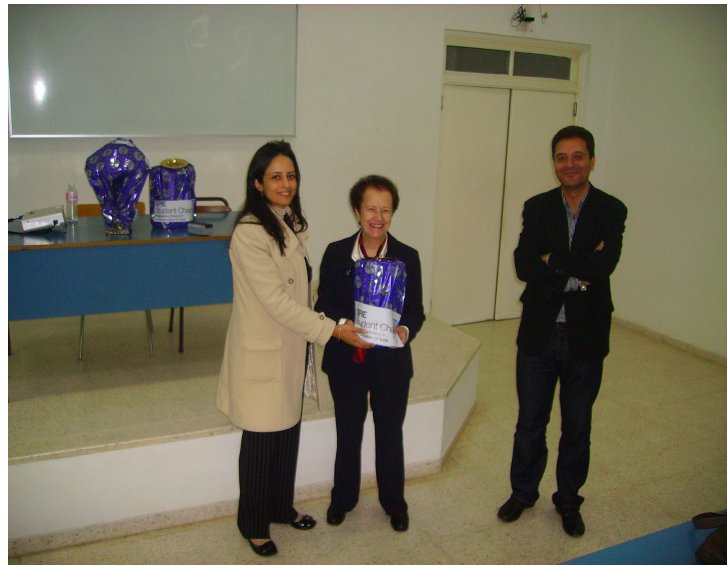

Prof. Maria Yzuel receiving a gift from the OPTSC.

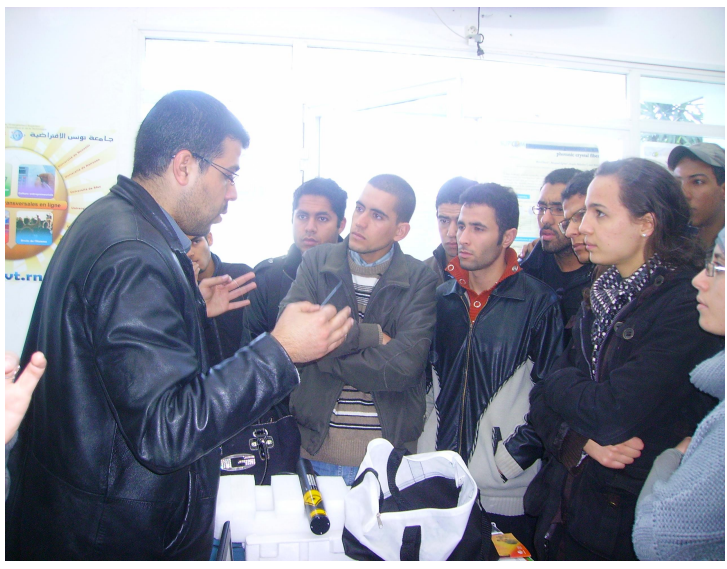

Booth set at the entrance of Sup'Com to explain the role of the Tunisian student chapter.

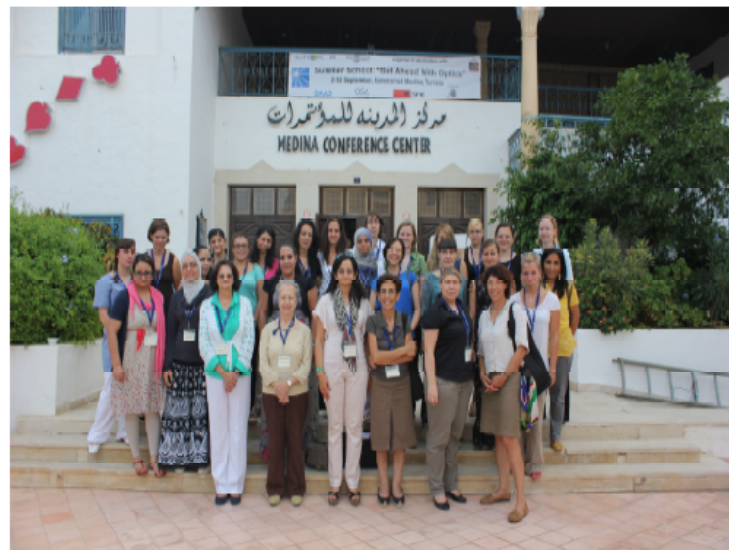

Group Photo during the" Get ahead with optics" school.

Figure 1. Professional development activities of the Tunisian student chapter. 
Another activity was launched through the involvement in the organization of the Summer School "GET AHEAD WITH OPTICS" which was held in Tunis in September 2012. The Tunisian student chapter participates in the organization of the summer school and preparing the best poster student award during the poster session. The interdisciplinary program is targeted towards female graduate students from Tunisia and Germany, which are interested in the field of optics, photonics, or measurement techniques. Its content and structure are designed to provide them with professional skills and help them succeed in the dynamic and rapidly evolving field of optics and photonics.
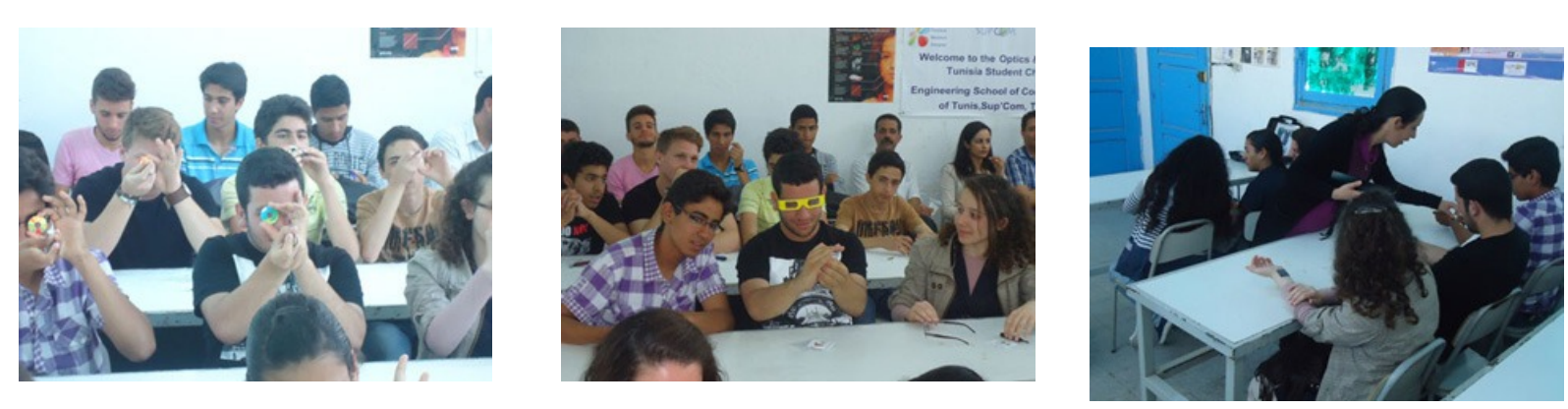

Rainbow PeepHole.

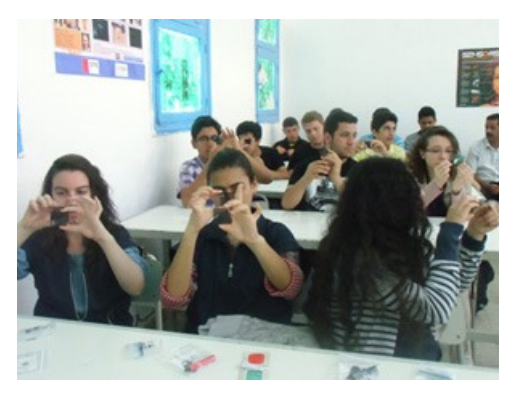

Magic Stripes.

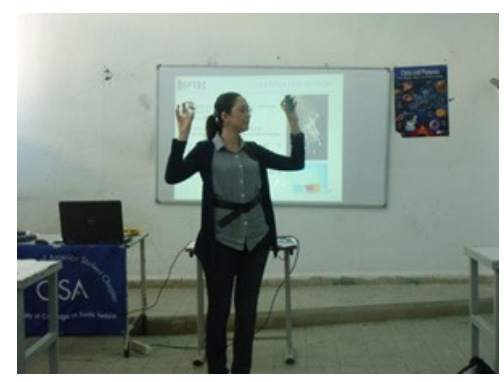

Silica Lens.
Rainbow Glasses.

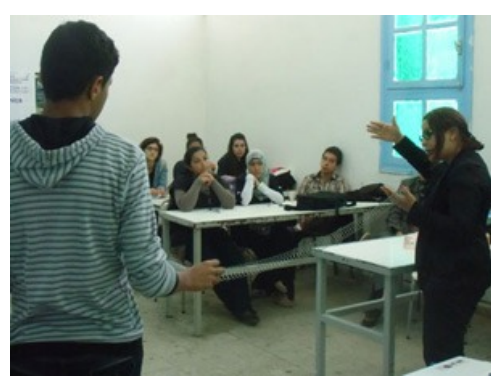

Slinky.

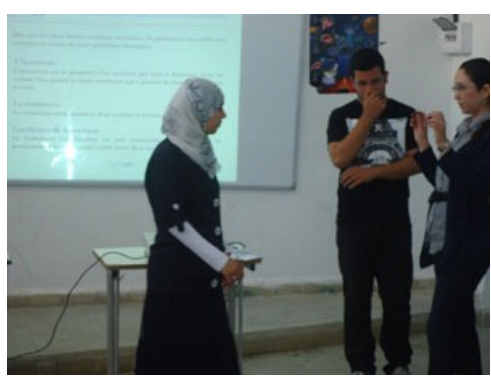

Happy - Unhappy Balls.
Magic Patch.

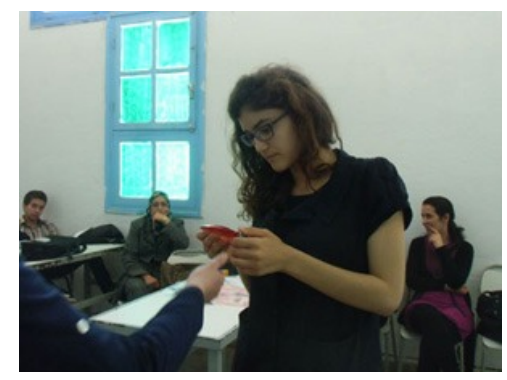

Heat patch.

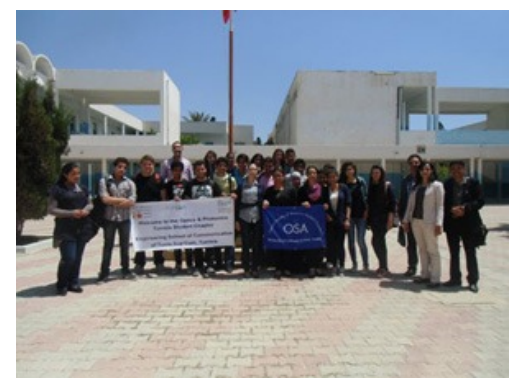

Group Photo.

Figure 2. Education outreach activities of the Tunisian student chapter.

Aiming to approach the optics and photonics knowledge to primary and secondary students and get young people excited about careers in technology with an important interest to the field, the African student chapters organized different activities from the north to the south of Africa.

The Tunisian student chapter organized in May 2013 an outreach activity for students of a secondary school in Hammamet, Tunisia (Fig. 2) to demonstrate the Optics Suitcase offered by OSA and containing different kits. About 30 
secondary school students were too excited and motivated; they were attentive to the demonstrations and asking many questions. The outreach activity was supported by 3 of their secondary teachers for kit demonstration. The optics suitcase is designed for classroom education purposes and to convey a sense of excitement about technology in a short period of time. Many theme packets have been used to explore color in white light and demonstrate different light physical properties, as seen from Fig. 2. In fact, by using rainbow Peephole, magic strips and magic patch kits, the students could be able to observe and distinguish between diffraction, polarization and selective reflection of light, respectively.

Therefore, the wave propagation has been demonstrated through a slinky component which represents a light wave vibration and creates a standing wave with few nodes. Moreover, material and chemical composition lesson has been presented to students through the silica lens experience by explaining the difference between silicon and dioxide silicon (silica) and then through the Happy and Unhappy Balls which are a pair of black spheres appearing to be almost identical but their composition and physical properties are different. Also, a Heat Pack showing a beautiful thermodynamics reaction in which the patch gets hot through the "trigger" inside. The trigger is a stainless steel disk that creates friction when the fluid is slowly forced through the tiny perforations in the disk during the flexing process.
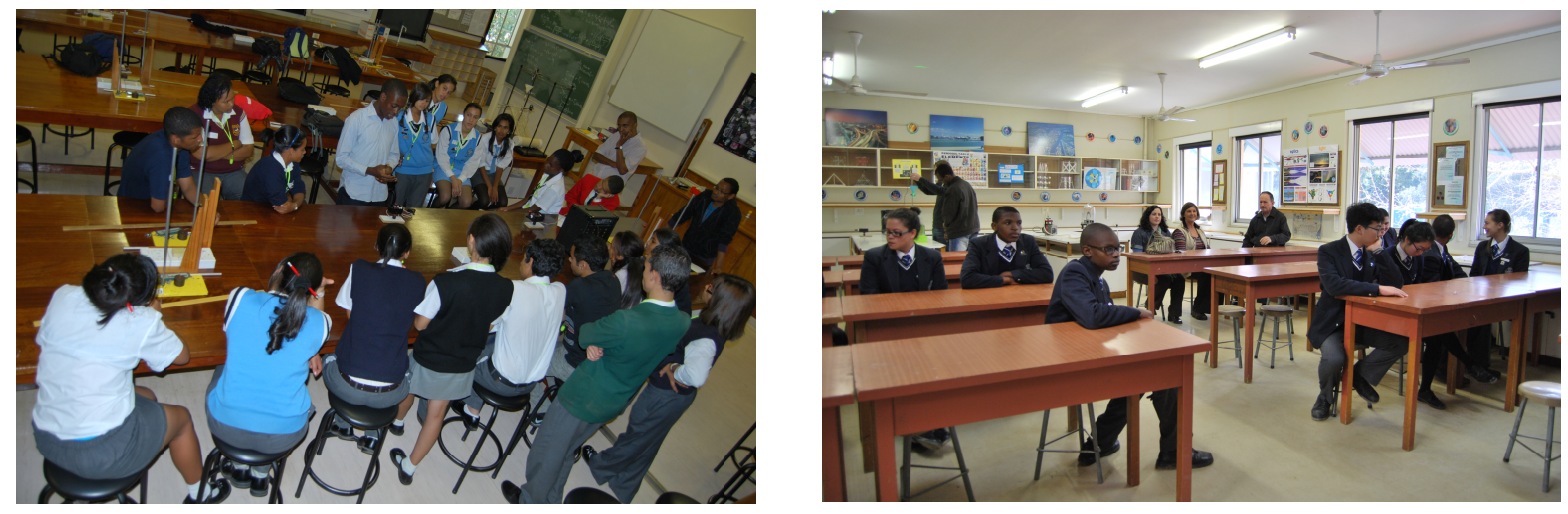

Local Outreach activities.

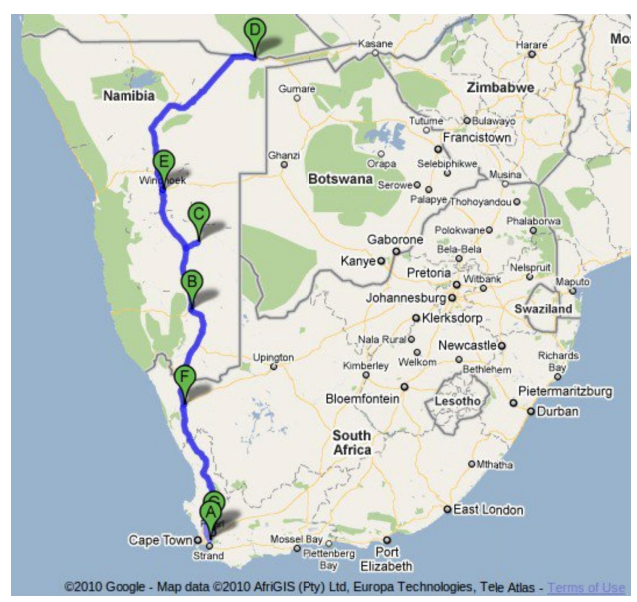

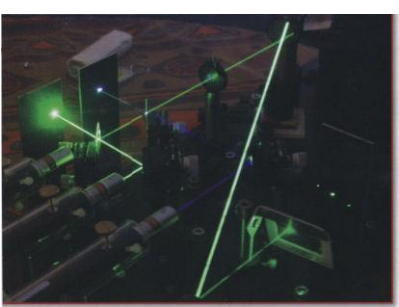

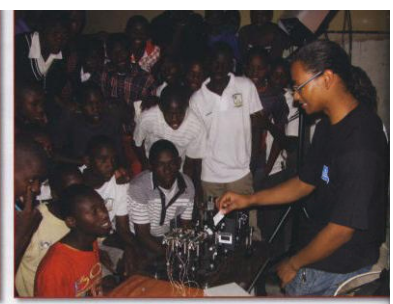

Bringing science to the people

Stellenboscn Laser Physics students tour through South Africa and Namibia with 'Colourful Optics' Roadshow. By Gillian Armstrong

Road trip: 2010 Namibia. 

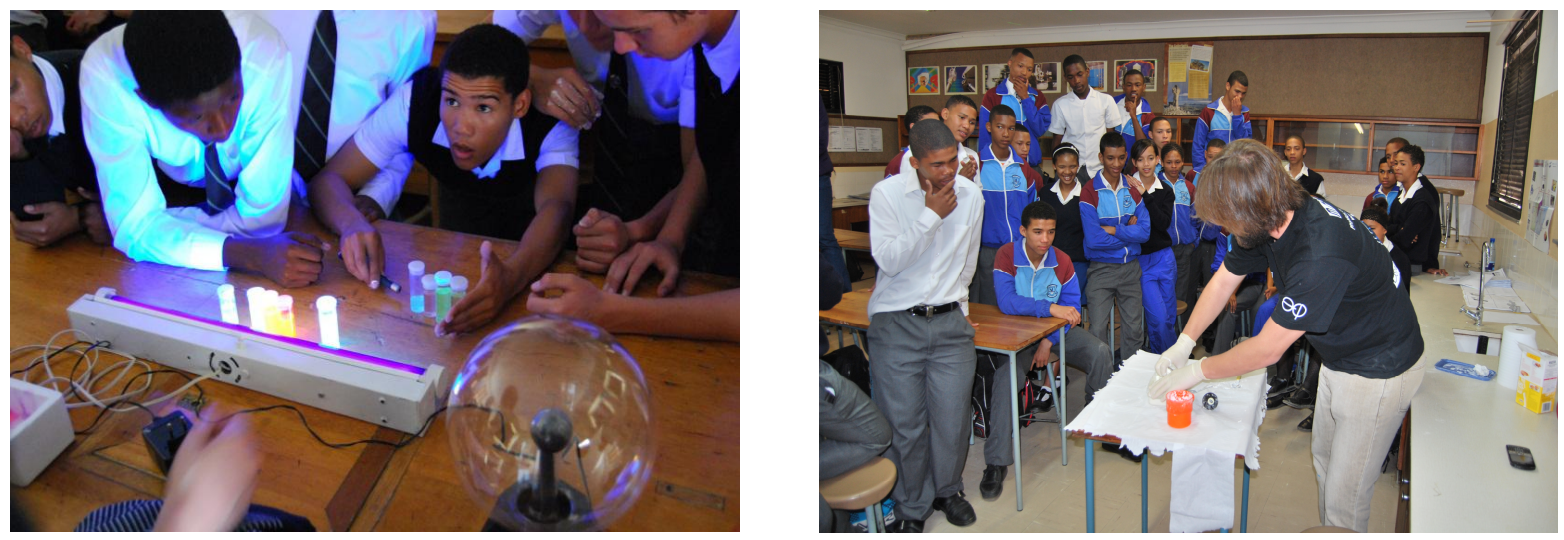

Road trip: 2011 West Coast.
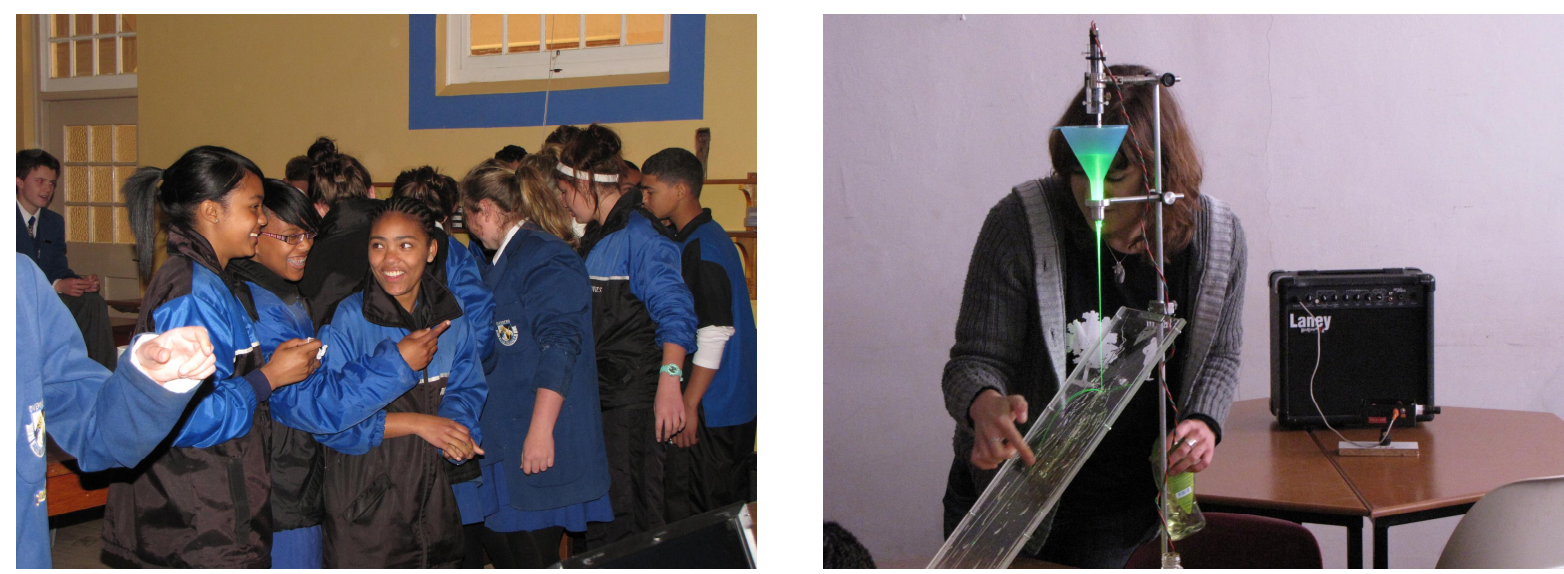

Road trip: 2012 Overberg.

Figure 3. Education outreach activities of the Stellenbosch University chapter.

An important education outreach activity has been performed in the south of Africa by the Stellenbosch University student chapter. It consists of a Traveling Outreach Project: Optics on the Road, as seen from Fig. 3. In fact, a diverse groups of students (based in the Laser Physics and Theoretical Physics groups at the department) launched the challenge and realized an education outreach road-trip in July 2010 aiming to bring a colorful and interactive presentation of lasers and optics to mark the 50th anniversary of the laser (see Fig. 3). Over 5000 kilometers through South Africa and Namibia were covered by using two vehicles and a trailer, and they visited 9 schools along the way - from private schools in Windhoek, the capital of Namibia, to rural schools in Nyangana at the Namibian-Angolan border. They presented an interactive science show at the schools, covering topics such as diffraction and refraction, the mixing of colors demonstrated using lasers, liquid crystals, basic properties and application of lasers, laser communication as well as fluorescence and phosphorescence. It is estimated that 600 students at various schools were reached. A video was compiled of the trip and links to it may be found on the "Stellenbosch Laser Student Chapter" Facebook page.

In addition to the local education outreach activity, the Physics Department at Stellenbosch University has continued to organize annual road trips. In 2011, they drove to several schools on the West Coast, and did Physics demonstrations there. Several schools were visited. A balance was kept between more rural, poor communities, and also more advanced schools. Each time presentations were adapted for the level of Physics education of the learners involved. Schools that were visited include Lutzville High School, two schools in Vredendal, Vanrhynsdorp High School, two schools in Clanwilliam, and schools in Graafwater and Citrusdal. 
As seen from Fig. 3, the demonstrations of the Stellenbosch University student chapter were pitched at a popular level, and drew on some of the school-based physics knowledge of the learners. The aim was to explain how physicists reason, how physical models are built, and how hypotheses of models are tested. In particular, they did demonstrations about the following topics: Non-Newtonian fluids (corn starch \& shampoo), Static electricity, phosphorescence, fluorescence, Modern telecommunication and 3D / stereo display technology.

One among the international events has been hosted for the first time by the CSIR National Laser Centre Student Chapter (see Fig. 4). It consists of the first IONS conference in Africa took place at Cathedral Peak Hotel in the Drakensberg in South Africa. It represents the International OSA Network of Students which connects people from around the globe, all actively engaged in optics and photonics. The first African IONS Conference took place from Friday 31 August till Sunday 2 September 2012, the weekend before an international conference: Quantum Africa 2, which also took place in the Drakensberg. This meant delegates had the option to attend both conferences for the cost of a single travel expense. The theme for the IONS1-Africa Conference was quantum and fiber optics, however all aspects of optics and photonics were welcomed. Moreover, visiting lecturers have been giving talks and remarkable numbers of students attending the event has been registered. An overview of the OSA and SPIE student chapter programme was presented to all the students. This was used as the basis for motivating students to start chapters at their Universities and Institutions. It had also been discussed that the African Laser Centre would like to start a student chapter of their own for all African students in Optics and Photonics. As a prerequisite it was requested that all students belong to an OSA and SPIE student chapter.

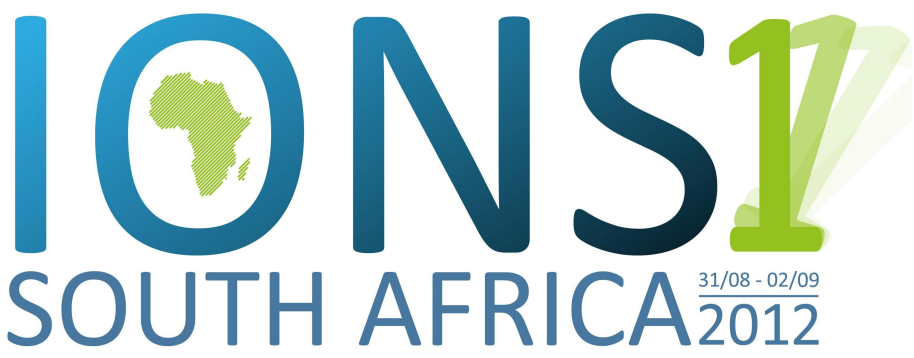

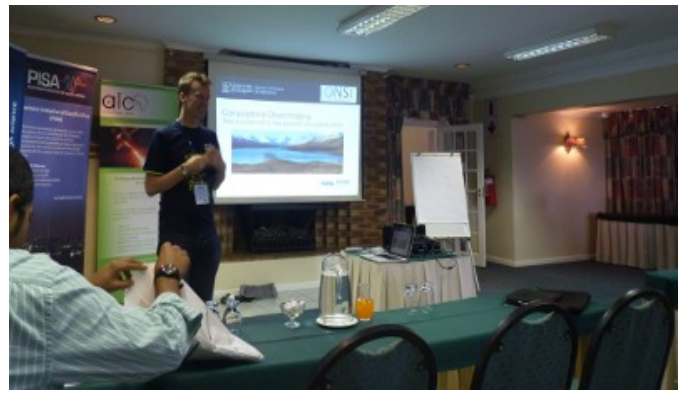

Talks given by Prof Miles Padgett (left)

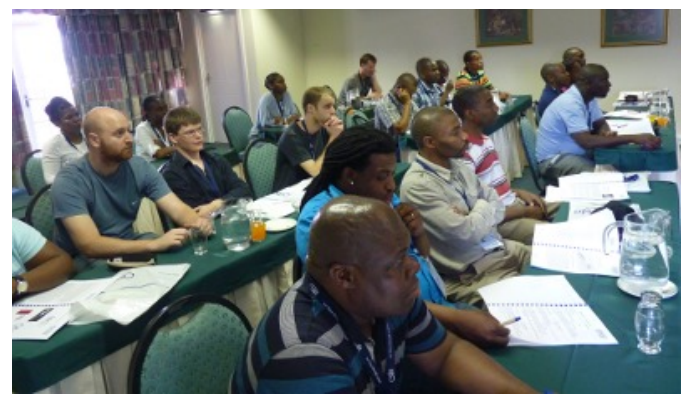

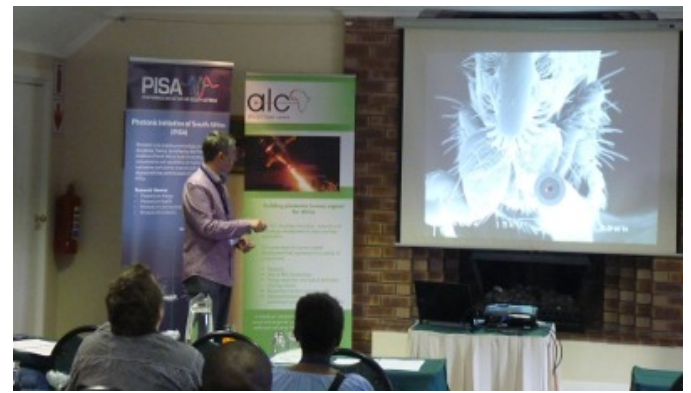

and Prof Tim Birks (right).

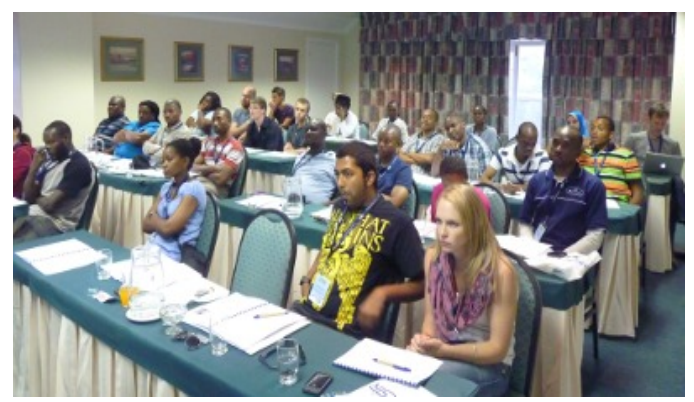

Delegates attending the talks.

Figure 4. IONS conference hosted by the CSIR student chapter. 


\section{FUTURE ACTIVITIES OF THE AFRICAN STUDENT CHAPTERS}

With the aim of spreading the optical knowledge to most of the African students from the south to the north, the CSIR Student chapter plans on hosting the first SPIE FOCUS event and through the experience gained from IONS Africa-1, they are fairly confident to have a successful event in 2014.

The Stellenbosch University student chapter is continuing his amazing traveling outreach project mission and looking forward to organizing another outreach road trip in 2013-2014.

The OPTSC will be involved during the First African Summer School on Optics and Applications to Sustainable Development (ASOSD) (www.school-tunisia-optics.org) which will be held in Tunis in September 2013. In fact, the Tunisian student chapter will organize and manage a poster and oral presentation student award that would be delivered for five scientific works ( 2 presentation awards and 3 poster awards).

\section{CONCLUSION}

A great opportunity to bring science to all the students in Africa has been surely realized through the student chapters. Wherever the geographical location, the student chapters from the south to the north showed their important commitment and roles to promote the field of optics and photonics through technical or social networking. By the organization of professional and educational outreach activities, a huge benefit has been reached to different graduate and undergraduate students. This will be for sure a great asset to these African student chapters to carry on and continue their educational tasks, inviting lectures program, and experimental demonstrations aiming to achieve the largest expansion of optics and photonics activities and disseminate this knowledge worldwide and through the African continent. 